Research article

\title{
Smallholder farmers' behavioural intentions towards sustainable agricultural practices
}

\author{
Woldegebrial Zeweld a, *, Guido Van Huylenbroeck ${ }^{\text {b }}$, Girmay Tesfay a , Stijn Speelman ${ }^{\text {b }}$ \\ ${ }^{a}$ Mekelle University, Natural Resource Economics and Management, Mekelle, Ethiopia \\ ${ }^{\mathrm{b}}$ Ghent University, Agricultural Economics, Ghent, Belgium
}

\section{A R T I C L E I N F O}

\section{Article history:}

Received 6 June 2016

Received in revised form

3 November 2016

Accepted 6 November 2016

\section{Keywords:}

Smallholders

Information

Sustainable practice

Decomposed theory of planned behaviours

Structural equation model

Northern Ethiopia

\begin{abstract}
A B S T R A C T
The introduction of sustainable practices is considered a win-win strategy for low-income countries because of its potential to simultaneously improve food security and address environmental issues. Despite the numerous studies that focus on the adoption of technological innovations, little work has been done on the socio-psychological behaviour of farmers with regard to sustainable practices. This study investigates smallholder farmers' intentions towards two practices: minimum tillage and row planting. The decomposed theory of planned behaviour is used as a theoretical framework to analyse the intentions. The findings reveal that attitudes and normative issues positively explain farmers' intentions to adopt both practices. Perceived control also has a positive significant effect on the intention to apply minimum tillage. When the intention is formed, farmers are expected to carry out their intention when opportunities arise. Moreover, perceived usefulness, social capital, and perceived ease of operation are also significant predictors of farmers' attitudes. Furthermore, social capital and training are factors that positively affect the normative issue, which in turn also positively mediates the relationship between training, social capital and intention. Finally, it is shown that neither the perceived resources nor information from the media significantly affect farmers' intentions. This paper thus confirms that social capital, personal efficacy, training and perceived usefulness play significant roles in the decision to adopt sustainable practices. In addition, willingness to adopt seems to be limited by negative attitudes and by weak normative issues. Therefore, to improve adoption of sustainable practices by smallholder farmers, attention should be given to socio-psychological issues. This could lead to improvements in farm productivity and enhance the livelihoods of smallholders.
\end{abstract}

๑) 2016 Elsevier Ltd. All rights reserved.

\footnotetext{
* Corresponding author.

E-mail address: wzeweld@gmail.com (W. Zeweld).

1 Sustainable agricultural practices include farming activities that have environmental, societal and economic dimensions such as conservation tillage, crop diversification, composting, biological control, improved varieties (crop/animal), agro-forestry, local seed conservation, rainfall harvesting, area enclosure, animal manure, water conservation, organic fertilizer, improved fallow management, forage management, and soil and water conservation (Mbow et al., 2014; Wezel et al., 2014; Kassie et al., 2013; Teklewold et al., 2013; Veisi and Toulabi, 2012). In this paper, sustainable (agricultural) practices refer to minimum tillage and row planting practices. Minimum tillage can be defined as the least possible amount of soil disturbance to prepare a suitable seedbed for successful crop production while row planting is a system of growing crops in a linear pattern (single or multiple) in at least one direction, rather than planting without any distinct arrangement. Both practices have several benefits such as saving resources (labor cost and energy consumption), conserving soil moisture, minimizing erosion, increasing gas exchange, minimizing pests and diseases, improving soil fertility and preventing excessive humidity. These advantages can, in turn, enhance yield, improve crop quality, and increase biodiversity, thereby generating more income opportunities and strengthening livelihood resilience (Vandercasteelen et al., 2014; Araya, 2012; Ekeberg and Riley, 1997).
}

\section{Introduction}

Sustainable practices ${ }^{1}$ and technological innovation play an important role in improving farm productivity, and enhancing food security and economic growth (Kassie et al., 2013; Teklewold et al., 2013; Asfaw et al., 2012) as well as improving soil fertility, reducing the risk of drought and water shortage, reducing erosion, and maintaining biodiversity and agroecosystem resilience (Mbow et al., 2014; Price and Leviston, 2014; Wauters and Mathijs, 2014; Wezel et al., 2014; Yazdanpanah et al., 2014; Foley, 2013; Power et al., 2013; Reimer et al., 2012; Veisi and Toulabi, 2012; Lee, 2005). Sustainable practices can involve reducing the use of inputs that are potentially harmful to the environment or a shift towards more locally available resources while maintaining the competitiveness and economic viability of agriculture (Wezel et al., 2014; Yazdanpanah et al., 2014; Veisi and Toulabi, 2012; Wollni et al., 2010; Wauters, 2010; Hattam, 2006). 
The introduction of improved technologies and the application of sustainable agricultural practices such as agroforestry, use of compost and manure, soil conservation practices, crop rotation, improved seed varieties, water harvesting schemes and intercropping in some Asian and Latin American countries has successfully improved the productivity of the agricultural sector and has significantly reduced food insecurity and poverty (FAO, 2014; Gumataw et al., 2013; Kelsey, 2013; Todaro and Smith, 2011; Dillon, 2011). Therefore, the adoption of improved technologies and sustainable practices has been considered an important agenda in the development policy of the Sub-Saharan African countries since the 1970s (FAO, 2014; Gumataw et al., 2013; Dillon, 2011; Norton et al., 2010).

In spite of this, the adoption of improved technologies and sustainable practices in these countries has remained below expectations. In the literature, several demographic and socioeconomic factors have been suggested as reasons for the low adoption (Mbow et al., 2014; Foley, 2013; Gumataw et al., 2013; Kassie et al., 2013; Kelsey, 2013; Teklewold et al., 2013; Asfaw et al., 2012; Reimer et al., 2012). However, there is still a lack of clear evidence to understand why/how farmers voluntarily adopt improved technologies and sustainable practices (Yazdanpanah et al., 2014). This indicates that there is still a need for further in-depth research on how smallholder farmers can be encouraged to use agricultural practices and technologies.

Previous studies have primarily focused on how demographic factors, economic resources, and biophysical factors affect the adoption of sustainable practices and technological innovation. A few studies have considered perception in relation to socio-psychological ${ }^{2}$ influence and access to an extension system to measure the impact of information sources. However, most studies overlook cognitive, social and psychological factors, as well as the influence of others' opinions and alternative information sources, in the analysis of decision behaviour (Martínez-García et al., 2013). As well as the sociopsychological issues, the characteristics of the agricultural practices themselves are also rarely considered (Wauters and Mathijs, 2014; Foley, 2013). Accordingly, most studies do not sufficiently capture socio-psychological behaviour (beliefs and social pressure) and alternative information sources. We believe that by using the theory of planned behaviour greater insight could be gained into people's behaviour (Borges et al., 2014), more specifically adoption decisions.

This issue has recently been highlighted by a few researchers (Borges et al., 2014; Wauters, 2010). Without considering the social-psychological issues, we may not fully understand the intentions and behaviour of farmers in adopting sustainable practices. Additionally, we need to understand the different information dissemination channels and their overall effects in influencing decision-making behaviour. This will help in targeting and integrating information channels that have more predictive power in their promotional campaigns for the adoption of sustainable practices and rural development programs. Therefore, this paper aims to understand farmers' attitudes and intentions as a basis for promoting sustainable practices.

The objectives of the paper are twofold. We first determine the attitudes and intentions of smallholder farmers towards the use sustainable practices on their plots in the future. Next, we explore the influence of attitudes, normative issues and perceived controls on farmers' intentions to adopt sustainable practices. This article contributes to the literature as follows. To our knowledge, this study is the first of its kind for the region under investigation (northern

\footnotetext{
${ }^{2}$ In this study, socio-psychological issues refer to a farmer's thoughts, feelings, attitudes and cultural norms regarding sustainable agricultural practices and also the influence of other reference groups and external forces on his behaviour and decisions.
}

Ethiopia) and it, therefore, provides insights for policy-makers and practitioners to design socio-psychological based initiatives or to readjust the current strategies designed to stimulate the adoption of sustainable practices. Secondly, the article contributes to the scarce literature on the adoption of sustainable practices which takes socio-psychological issues into account. Finally, it will test whether the decomposed theory of planned behaviour adequately explains Ethiopian farmers' intentions to adopt sustainable practices.

This article is organised into five main sections. Section 1 introduces the problem and the objective of the study. The theoretical and conceptual frameworks of the study are reviewed and explained in the section 2. In this section, the hypothesis is also established and the model is explained. Following this, the research design is described including the sampling framework, data collection and data analysis. The assumptions of the structural equation model are briefly assessed and evaluated here. The fourth section presents the results and discusses the main findings of the study. Finally, conclusions and policy implications are given.

\section{Review of literature}

\subsection{Theoretical and conceptual frameworks}

The theory of reasoned action is one of the theoretical frameworks that seek to explain human behaviour and adoption decisions. It assumes that human behaviour is under full volitional control and postulates intention, which is captured by attitude and subjective norm, to explain a given behaviour (Fishbein and Ajzen, 1975). However, Ajzen (1991) later criticised the full volitional control assumption. Not all human behaviour is completely under volitional control, since some behaviour relies on external factors. Therefore, Ajzen proposed the theory of planned behaviour, which added perceived control to the existing components of behavioural intention. Under this theory, intention becomes a weighted function of attitude, subjective norm, and perceived control. Both perceived control and intention also explain the adoption behaviour (use) of technologies.

However, the theory of planned behaviour was also criticised by Taylor and Todd (1995) for its monolithic structure of belief. They rejected the uni-dimensional belief and constructed the multidimensional belief. The cognitive component of the belief structure cannot be organised into a single conceptual unit because it is grounded in different ideas. They proposed the decomposed theory of planned behaviour, which further decomposed the attitudinal belief structure into perceived usefulness, perceived compatibility and perceived ease of operation (perceived easiness), and the perceived control into self-efficacy and facilitating conditions. Consequently, according to this theory, behavioural intention becomes a function of several lower-level behavioural constructs.

For this study, the decomposed theory of planned behaviour, which combines the theory of planned behaviour, diffusion of innovation theory ${ }^{3}$ and economic constraint theory, ${ }^{4}$ is used as a theoretical basis to develop our conceptual framework (Fig. 1) to explain smallholder farmers' intentions to adopt sustainable agricultural practices. Farmers' intentions to adopt sustainable practices is explained by attitude, perceived control, and normative issues. In line with the decomposed theory of planned behaviour, attitude is

\footnotetext{
${ }^{3}$ Identifying four factors (technology attributes, communication channels, time and social system) that affect the use and spread of a new technology (Rogers, 1983).

${ }^{4}$ Explaining how the distribution of resources such as land, capital, labor, liquidity and other inputs explain the use and spread of a new technological innovation (Wollni et al., 2010).
} 


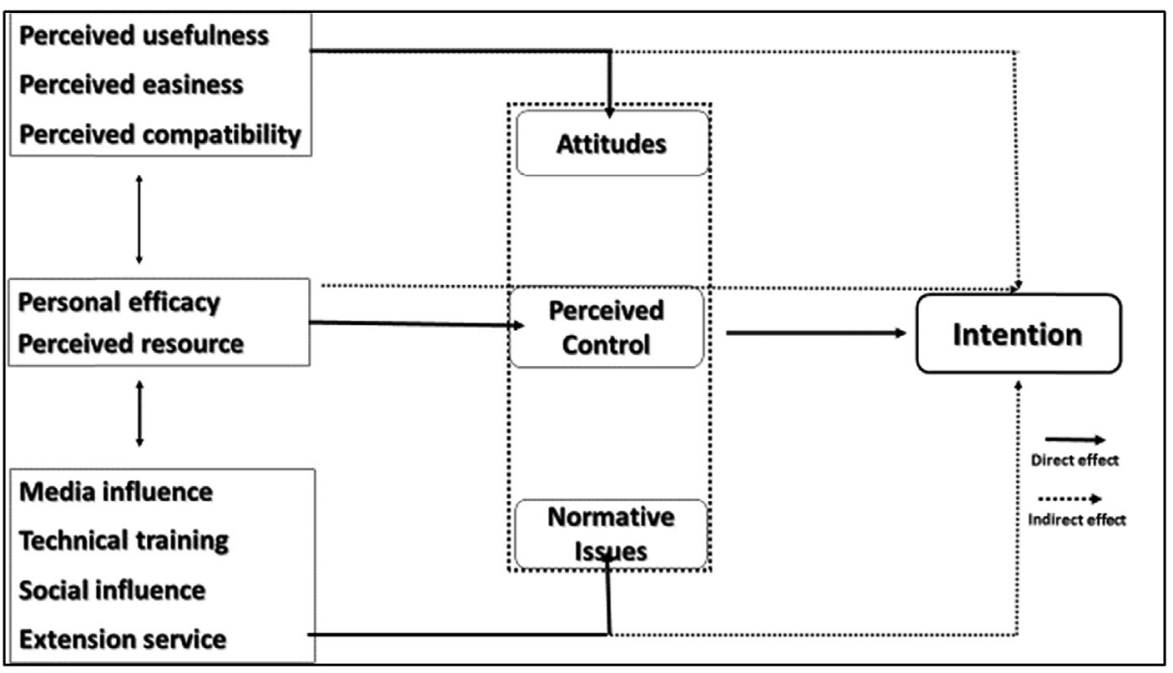

Fig. 1. Conceptual framework for behavioural intention towards sustainable agricultural practices.

decomposed into perceived usefulness, perceived ease of operation, and perceived compatibility, whereas the perceived control is split into personal efficacy and perceived resources in order to provide comprehensive information and explanation about intention.

While, economic resources, personal motivation, and attributes of the practices seem to provide good information about intentions and behaviour they are not sufficient, because communication channels and social systems also affect adoption decisions (Rogers, 1983) and adoption occurs in a social context with a dynamic and reciprocal interaction between individual and his environment (Venkatesh et al., 2012). To capture the overall pressure of social groups and communication forces on behaviour and decisions, we further structure normative issues into media influence, technical training, extension services and social capital/social influence, following the social cognitive ${ }^{5}$ and diffusion of innovation theories.

In this study, the normative issue can serve as a proxy factor for information, innovation, and uncertainty. Mass media, friends, family, training, extension workers, and neighbours can make the users aware of sustainable practices (knowledge), to form attitudes to evaluate the attributes of the practices (persuasion), to reduce uncertainty about the advantages and disadvantages of the practices (decision), to adapt the practices to their own farm environment (implementation) and to reinforce their decision and influence other groups (confirmation) (Venkatesh et al., 2012; Rogers, 1983). The normative issue is thus a catalyst factor throughout all the stages of adoption of sustainable practices.

This conceptual framework ${ }^{6}$ thus combines the theory of planned behaviour, social cognitive theory, diffusion innovation theory and economic constraint theory. It uses multidimensional beliefs,

\footnotetext{
${ }^{5}$ This theory describes how the context of social interaction, experience, and media influence explains the acquisition and adoption of technological innovation (Venkatesh et al., 2012).

${ }^{6}$ Our conceptual framework is blended from four theories. Since the theory of planned behaviour that links how beliefs (attitudes, normative issues, and perceived controls) explain farmers' intentions and behaviour towards using sustainable agricultural practices is not adequate to explain human intention and behaviour, perceived control is decomposed into personal efficacy and perceived resource, based on the concept of economic constraint theory and social cognitive theory. We also split attitudes into perceived usefulness, perceived compatibility and perceived ease of operation following the concept of diffusion of innovation theory. Finally, taking into account the concepts of diffusion of innovation and social cognitive theories, the normative issue is decomposed into media influence, social capital, technical training, and extension services. Following this, our model adequately explains the intention and adoption decisions for sustainable agricultural practices.
}

which may produce sound findings and have a better forecasting power than monolithic beliefs. Finally, it allows the establishment of a crossover relational effect (interaction) between the predictors. Overall, our conceptual model helps to better understand and explain farmers' intentions towards sustainable agricultural practices.

\subsection{Previous empirical studies}

The theory of reasoned action, theory of planned behaviour and decomposed theory of planned behaviour have often been applied intensively in empirical studies relating to consumer behaviour, manufacturing industries, advertising campaigns, information technologies and software sciences (Iqbal and El-Gohary, 2014; Zschocke et al., 2013; Sadaf et al., 2012; Velarde, 2012; KyereDuodu, 2011). However, in the field of agriculture, natural resource management and rural development their use has been limited. Attitudes, subjective norms and perceived control were found to positively influence farmers' intentions to use rice variety innovations in India (Yamano et al., 2013), to use improved grassland management practices in Brazil and Mexico (Borges et al., 2014; Martínez-García et al., 2013), to manage riparian and water-zone areas sustainably in Australia (Fielding et al., 2005), and to adopt sustainable practices in paddy production in Malaysia (Terano et al., 2015). Attitudes, past behaviour, and cultivated acreage size were found to be significant factors in the intentions to adopt sustainable practices in Italy, while subjective norms and perceived controls were insignificant motivators (Menozzi et al., 2015).

Following Läpple and Kelley (2010) and Hattam (2006), the conversion from conventional farming to organic farming in Ireland and the UK was significantly affected by subjective norms, perceived ease of conversion, perceived control and the ability of farmers to convert. However, attitude had an insignificant influence on the intention to convert to organic agriculture. Studies in Iran also showed that attitudes, perceived risks, subjective norms and moral norms positively influenced the intentions of farmers to use water conservation practices (Yazdanpanah et al., 2014), and attitude was found to be a significant factor in farmers' intentions to use climate information in farming practices, while subjective norms and perceived control were not found significant (Sharifzadeh et al., 2012). The mean scores for attitude and subjective norms towards environmentally oriented behaviours were higher for organic farmers than conventional farmers, but the 
opposite held true for production-oriented behaviours (Power et al., 2013).

Wauters (2010) found that, in Belgium, attitudes and perceived control were insignificant factors in affecting the intentions of farmers to adopt reduced tillage and buffer strips, while subjective norms were found to have a positive significant influence on both sustainable practices. In the Czech Republic, attitudes and perceived control, along with education and age, have explained intentions to use agricultural technologies (Herath, 2013). Several studies found a positive relationship between farmers' attitudes and perceptions towards environmentally sustainable programs. It was confirmed that attitude alone was unable to predict farmers' behaviour towards sustainable practices (Price and Leviston, 2014; Herath, 2013; Veisi and Toulabi, 2012; Wollni et al., 2010; Bayard and Jolly, 2007; Jordan, 2005). Thus, the previous studies produced mixed findings and it is clear that one predictor alone is unable to predict farmers' behaviour and decisions.

\subsection{Hypothesis and definition of variables}

The study considers four endogenous latent variables (intention, attitude, perceived control and normative issues) and several exogenous latent variables (media influence, technical training, social capital, extension services, perceived usefulness, perceived ease of operation, personal efficacy, perceived compatibility and perceived resources). A definition of the items used is given in Table 1. These socio-psychological variables are latent or unobserved variables and multiple observed indicators or statements are used to measure them. Each statement is graded or anchored by a five-point Likert scale that ranges from completely disagree to completely agree and from more unlikely to more likely. We expect the exogenous latent variables to influence the endogenous latent variables and the following hypotheses are proposed following the conceptual framework and based on results from previous empirical studies.

H1. The majority of the smallholder farmers have positive attitudes and intentions towards minimum tillage and row planting practices.

H2. Intention of farmers towards minimum tillage and row planting is positively related to attitudes, normative issues, and perceived controls.

H3. Attitude mediates the positive effects of perceived usefulness, perceived ease of operation, and perceived compatibility on the intentions of farmers.

H4. Farmers' intentions to use minimum tillage and row planting is positively (indirectly) affected by media influence, social capital, technical training and extension services.

H5. Perceived control mediates the positive effects of personal efficacy and perceived resource on the intention of farmers.

\subsection{Model estimation and explanation}

In line with Lobb et al. (2007), three estimation procedures are used to verify the hypotheses and to investigate factors that influence farmers' intentions. The latent variables are assumed to be proportional to a linear combination of the observed statements contributing to the latent variables (Lobb et al., 2007; Taylor and Todd, 1995). A principal component analysis is used to determine the number of underlying factors with a homogenous structure from the heterogeneously observed statements. This can be expressed as follows:
$L V_{j}=w_{t} \sum_{i=1}^{n} X_{t}$

Where $L V_{j}$ is a latent variable ' $j$ ' such as intentions, attitudes, normative issues or perceived controls that can be derived from multiple observed statements $\left(X_{t}\right)$ which are collected from ' $n$ ' individuals and $w_{t}$ is the weighted index for each observed statement ' $t$ ' that is loaded in the corresponding latent variable. After specifying the desired factors, the value of the latent variables is determined based on the expectancy-value (mean score) method.

However, there is an indirect interaction, or endogenous relationship, between the latent variables. For example, attitudes can be directly determined by perceived usefulness, but this can also indirectly interact with others such as social capital. Accordingly, the second procedure is to estimate the relationship between the latent variables to account for the interdependency (Lobb et al., 2007). A system of simultaneous equations allows us to capture the interaction and simultaneity problem. The generic system can be defined as follows:

$L V_{s}=f\left(L V_{k}\right) \quad$ if $s \neq k \quad s=1,2, \ldots, m ; \quad k=1,2, \ldots, m$

Where, latent variable ' $S$ ' $\left(L V_{S}\right)$ interacts with latent variable ' $K$ ' $\left(L V_{k}\right)$.

Finally, we estimate the path coefficients of the variables for the behavioural intention. This is a (direct or indirect) linear function of the derived latent variables. A linear structural equation model that captures potential causal dependency between the derived endogenous and exogenous latent variables and includes the necessary information (e.g., the means, covariance matrix and measurement errors) is used to estimate intentions and is given as follows:

$I B_{i}=\sum_{i=1}^{n} \beta_{i} L V_{i h} \quad$ where, $L V_{i h}=\sum_{i=1}^{n} \alpha L V_{i v} \quad h \neq v$

Where $I B_{i}$ represents the intention of smallholder farmer ' $i$ ' towards sustainable practices. This is linearly (directly) explained by the derived latent variables $\left(L V_{h}\right)$ as well as linearly (indirectly) explained by the latent variables $\left(L V_{v}\right)$. In the structural model, the data are assumed to follow a multivariate normal distribution and a maximum likelihood estimation method can thus be applied.

\section{Materials and method}

\subsection{Study area and sampling procedure}

This study was conducted in Atsbi-Wemberta district in Ethiopia (See Fig. 2). This is one of the drought-prone areas in the country. Its environment is highly degraded due to natural and human factors. More than a quarter of the population is food insecure and many young people have migrated in search of jobs and better lives. In this light, several community-based development programs have been implemented in the area and farmers have been encouraged to adopt a number of sustainable practices to improve yields and to overcome food insecurity. This makes the district appropriate to undertake research that focuses on sustainable agricultural practices.

The district is composed of 18 villages. They belong to two agroecological zones. Two villages are found in the warm temperate zone (1500-2300 $\mathrm{m}$ above sea level) and 16 villages in the temperate zone (2300-3250 $\mathrm{m}$ above sea level). Two villages from the temperate zone (Haikimeshal and Endasilassie) were excluded from the study because they are too urbanized. Using a lottery method, five villages 
Table 1

Definition and explanation of terms and concepts (latent variables) in the framework for the current study.

\begin{tabular}{|c|c|}
\hline Variables & Description of the variables \\
\hline Attitude & The degree to which a farmer feels inclined towards adopting a sustainable practice after evaluating its positive and negative consequences \\
\hline Normative issues & $\begin{array}{l}\text { The degree to which a farmer believes that reference groups and information channels influence his behaviour and decisions. This is broader than the } \\
\text { subjective norms because it also includes the effect of communication channels. }\end{array}$ \\
\hline Perceived control & $\begin{array}{l}\text { The perception of how difficult or easy it is to adopt a practice. This depends on internal and external obstacles or opportunities such as personal } \\
\text { abilities, knowledge, economic resources and infrastructure facilities }\end{array}$ \\
\hline $\begin{array}{l}\text { Perceived } \\
\quad \text { usefulness }\end{array}$ & The degree to which a farmer believes that sustainable practices will improve outcomes such as yield, soil fertility, food security or income. \\
\hline Perceived easiness & The degree to which a farmer perceives the sustainable practices to be easy to understand, learn or operate \\
\hline $\begin{array}{l}\text { Perceived } \\
\text { compatibility }\end{array}$ & The degree to which a farmer believes that the sustainable practices fit with his existing traditional values, previous experience, and current needs. \\
\hline Personal efficacy & The level of confidence a farmer has that he can successfully adopt the practices, relying on his skills, competencies and knowledge. \\
\hline Perceived resources & $\begin{array}{l}\text { The degree to which a farmer perceives that he owns the necessary resources (money, labour, time and capital) and technical infrastructure to } \\
\text { support him in adopting the sustainable practices. }\end{array}$ \\
\hline Media influence & The overall influence on behaviour and decisions by information from formal media such as television, radio, telephone, newspapers and magazines \\
\hline Technical training & $\begin{array}{l}\text { The effect on behaviour and decisions by capacity-building training such as short-term training, workshops, agricultural field days, experience } \\
\text { sharing, on-farm demonstrations and exposure visits. }\end{array}$ \\
\hline Extension service & The degree of influence on behaviour and decisions by information or consultation with agricultural advisory experts, and extension workers \\
\hline Social capital & $\begin{array}{l}\text { The influence on behaviour and decisions by significant reference groups, such as friends, neighbours, families, communities, children, schooling, } \\
\text { local leaders, traditional groups, and rural associations. }\end{array}$ \\
\hline
\end{tabular}

from the temperate zone (Hayelom, Michael Emba, Habes, Felege Weyni and Ruba Feleg) and one village from the warm temperate zone (Eira) were randomly selected. About 9500 household heads live in these villages and we determined our sample size (350 farmers) following the Yamane (1967) formula, which we proportionally allocated to each village. Finally, using the sampling frame in each village, the target farmers were randomly selected.

In consultation with agricultural experts in the region, many sustainable practices were identified, including soil and water conservation, agroforestry, biological control, crop rotation, row planting, crop diversification, application of compost, use of farmyard manure, minimum tillage, area enclosure, zero-grazing and weed management. These practices were categorised as (a) commonly applied in the last five years (b) barely adopted or only introduced recently. Biological control of pests and diseases, use of biodegradable pots, row planting, and minimum tillage belong to the last category. From these, row planting and minimum tillage were randomly selected to explore the socio-psychological influence on farmers' intentional decisions towards these practices.

\subsection{Data collection and analysis}

A review of the literature, a pilot study and group discussions were undertaken to develop the questionnaire used to collect the data. A preliminary and informal discussion took place with purposively selected extension workers. Previous studies on sustainable practices and behavioural approaches were reviewed to gain insight into the theme. Both have enabled us to broaden our understanding of the agricultural practices and to prepare a draft questionnaire. Subsequently, a pilot survey with 10 randomly selected farmers was conducted to contextualise the questionnaire. The farmers who had participated in the pre-test were excluded from the final study. Based on the feedback during the pilot, a final questionnaire was developed. The study uses a principal component analysis with oblique rotation to determine latent variables with a homogenous and common structure from a large number of heterogeneously observed statements in the questionnaire. Linear structural equation modelling with maximum likelihood estimation is applied to estimate the potential causal dependency between the latent variables. This allows exploration of farmers'

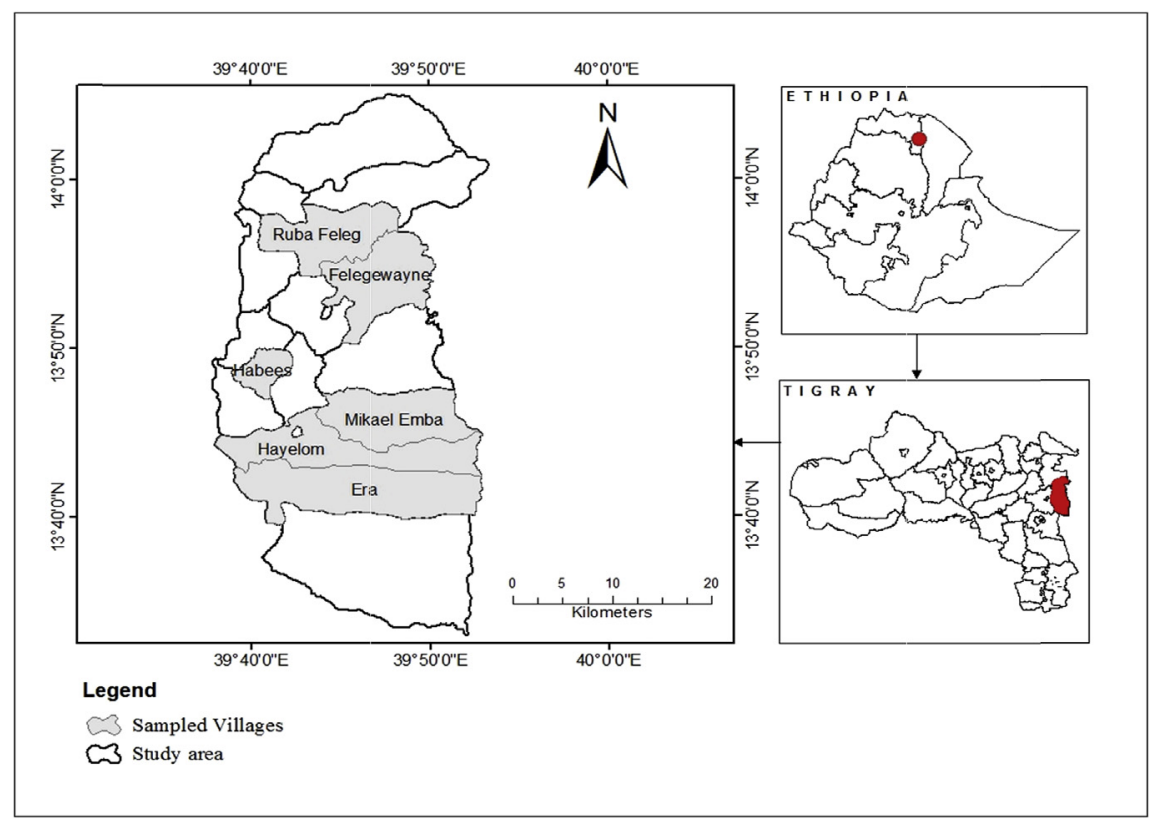

Fig. 2. Map of the study area situation within Ethiopia, Tigray and the district. 
intentions towards adopting different sustainable practices. STATA 13 and SPSS-AMOS 22 were used for the data management.

\subsection{Evaluation of assumptions for the structural equation model}

As stated in section 2.3, the variables considered are latent and they are measured through observed statements. We use a Bartlett principal component analysis with oblique target rotation ${ }^{7}$ to determine the statements underlying the latent variables or factors with a common structure. The Kaiser-Meyer-Olkin test statistic for minimum tillage is 0.73 and that for row planting is 0.80 . This indicates that the sample size is adequate to undertake a principal component analysis. About 50 statements are used in the survey both for row planting and minimum tillage. The statements are loaded into 13 factors or latent variables specifying a threshold for retention (Eigenvalue) of one and above. The retained factors explained about $73 \%$ and $82 \%$ of the available variance for minimum tillage and row planting, respectively. Intention, attitude, normative issues, technical training, social capital and personal efficacy factors are respectively loaded by six, four, five, four, five and five observed statements, while other factors are loaded by three statements.

After determining the number and values of the latent variables or factors, a number of assumptions were checked because a structural equation model is sensitive to sample size, normality, and multicollinearity. A structural model also requires latent variables to be reliable and valid (Kline, 2011; Wauters, 2010). As a rule-of-thumb, Kline suggested a minimum sample size of 200 for applying a structural equation model. Our sample, with 350 respondents is, therefore, suitable for the use of a structural equation model.

We use several iterations to check reliability and validity of the latent variables. The statements in the survey, which are required to construct the latent variables, are adapted from previously validated studies, such as Venkatesh et al. (2012), Wauters (2010) and Taylor and Todd (1995) and they were contextualized through a preliminary assessment and pilot survey to improve the logical flow of the questions and to enhance the quality. Finally, we used the Cronbach alpha $(\alpha)$ to test reliability, and average factor loading $(\mathrm{AFL})$ and average variance extracted $(\mathrm{AVE})^{8}$ for validity. The coefficients of $\alpha$, AFL and AVE are found to be higher than the recommended level. We, therefore, conclude that the latent variables are reliable and valid. Thus, the observed statements that are loaded to the underlying latent variables can adequately be loaded into the derived latent variable (See Annex A).

Skewness is used to check for normality of the data. The value of the Skewness for each variable does not deviate from the univariate normality assumption. The multivariate normality $\left(\mathrm{P}\left(\chi^{2}\right)=0.000\right)$ also indicates that the variables do not seriously violate the

\footnotetext{
7 In principal component analysis, the OLS regression method is used when there is correlation between factor scores, while the Bartlett and Anderson-Rubin method is applied when the factor scores are uncorrelated. The exact choice of rotation depends on whether the underlying factors are related. If there are theoretical grounds to think that the factors are independent or unrelated, the orthogonal rotations (e.g. varimax) are chosen. The oblique rotations (direct oblimin or promax) are used when theory suggests that the variables may correlate (Kline, 2011). Based on the decomposed theory of planned behaviour, we assumed that the latent variables are theoretically related and therefore oblique rotation is applied.

${ }^{8}$ Average factor loading is the mean of the degree to which multiple statements to measure the same concept or latent variable are in agreement; average variance extracted is the average amount of variance in the statements accounted for by the latent variable; Cronbach alpha shows how well or internally consistent the multiple statements are in explaining the latent variable; and Skewness is used to check the probability distribution of a random variable. As a rule-of-thumb, the minimum value for Cronbach alpha, average factor loading and average variance extracted in behavioural research is respectively $0.70,0.60$ and 0.50 , while the coefficient of Skewness for normality ranges between positive and negative one, but is preferably close to zero (Kline, 2011).
}

normality condition. The central limit theorem also confirms that the variables are normally distributed. Based on 2-tailed Pearson moment correlation analysis, we found that the variables are statistically uncorrelated to one another, with the exception of the perceived compatibility which is strongly correlated with perceived resources (correlation coefficient $=-0.15$ ) for the case of minimum tillage, as well as personal efficacy with perceived compatibility (correlation coefficient $=0.27$ ) and with perceived ease of operation (correlation coefficient $=-0.11$ ) for the case of row planting (Annex B). It was nevertheless decided to keep these variables, because dropping them did not significantly change the model. It can, therefore, be concluded that no serious problems of nonnormality and multicollinearity are present in this study.

\section{Results and discussion}

\subsection{Smallholder farmers' attitudes and intentions towards the use of sustainable practices}

This section aims to understand and examine attitudes and intentions of smallholder farmers towards sustainable practices such as minimum tillage and row planting. Based on a principal component analysis, six observed statements are loaded to the intention factor. These include - intend to adopt sustainable practices in plots the following year; intend to encourage neighbours to engage in sustainable practices; how strong is the intention to adopt sustainable practices in the future; aim to use less biocide inputs and more sustainable practices; do you think sustainable practices would improve farm productivity and yield; and how likely do you believe that adoption of the practices will improve income and livelihood. The responses are graded on a five-point Likert scale and range from strongly disagree to strongly agree. These statements explained the intention of about 78\% for row planting and $66 \%$ for minimum tillage.

Attitude is another latent variable that is loaded by four different statements, which include use of sustainable practices in plots next year would be a wise idea (very bad - very good), is an important instrument to improve agricultural productivity and yield (very unimportant-very important), is an advantageous instrument to enhance fertility of farmland and to enrich biodiversity (very disadvantageous-very advantageous), and is a necessary input to improve income and livelihood (very unnecessary-very necessary). The responses are anchored by five-point Likert scales and these four statements explained attitude for approximately $79 \%$ for row planting and $67 \%$ for minimum tillage.

Using an index formula developed by Tam and Coleman (2011), we constructed the value of attitude/intention from the observed statements and this ranged from zero to one. We grouped these levels as highly positive $(1.00-0.80)$, positive $(0.79-0.60)$, indeterminate or neutral $(0.59-0.40)$, negative $(0.39-0.20)$ and highly negative (0.19-0.00). However, for statistical comparison purposes, we converted these five groups into three groups: positive (highly positive and positive), undecided or undefined and negative (highly negative and negative). Table 2 presents smallholder farmers' attitudes towards row planting and minimum tillage and intentions to apply these practices.

About $61 \%$ and $74 \%$ of the respondents have a positive attitude towards adoption of minimum tillage and row planting, respectively. The percentage of respondents who have a negative attitude towards both sustainable practices is about $8 \%$. The remaining respondents have a neutral or undecided attitude towards the practices. Similar studies, for example, found that more than half of sample farmers in Italy had positive attitudes towards adoption of sustainable practices (Menozzi et al., 2015); to use improved grassland management practices in Mexico (Martínez-García et al., 2013); to use climate 
Table 2

Farmers' attitudes and intentions toward adopting sustainable agricultural practices.

\begin{tabular}{|c|c|c|c|c|c|c|c|c|c|c|}
\hline \multirow[t]{2}{*}{ Latent Variables } & \multirow[t]{2}{*}{ Likert scales } & \multicolumn{4}{|c|}{ Row planting practices } & \multicolumn{4}{|c|}{ Minimum tillage practices } & \multirow[t]{2}{*}{$\chi^{2}$} \\
\hline & & Mean & Freq. & $\%$ & Rank & Mean & Freq. & $\%$ & Rank & \\
\hline \multirow[t]{3}{*}{ Attitudes } & Positive & 0.80 & 258 & 74 & 1 & 0.68 & 214 & 61 & 1 & \multirow[t]{3}{*}{$0.025^{* *}$} \\
\hline & Undefined & 0.48 & 62 & 18 & 2 & 0.48 & 110 & 31 & 2 & \\
\hline & Negative & 0.24 & 30 & 8 & 3 & 0.31 & 26 & 8 & 3 & \\
\hline \multirow[t]{3}{*}{ Intentions } & Positive & 0.77 & 252 & 72 & 1 & 0.68 & 189 & 54 & 1 & \multirow[t]{3}{*}{$0.019^{* * *}$} \\
\hline & Undefined & 0.49 & 69 & 20 & 2 & 0.49 & 135 & 39 & 2 & \\
\hline & Negative & 0.33 & 29 & 8 & 3 & 0.30 & 26 & 7 & 3 & \\
\hline
\end{tabular}

Note: ${ }^{*}{ }^{* *}$ and ${ }^{* * *}$ shows statistically significant at $10 \%, 5 \%$, and $1 \%$ levels, respectively.

information for technological innovations in Iran (Sharifzadeh et al., 2012); and towards environmental practices in rural Haiti (Bayard and Jolly, 2007). Overall, most farmers in the area have positive attitudes towards adoption of sustainable practices.

As shown in Table 2, about $54 \%$ of respondents have a positive intention to use minimum tillage, whereas the corresponding figure for row planting is about $72 \%$. About $20 \%$ and $39 \%$ of respondents have an undefined intention for row planting and minimum tillage, respectively. About $8 \%$ of respondents have a negative intention for row planting and about $3 \%$ for minimum tillage. The intention of the majority of the respondents towards both sustainable practices is, therefore, positive. This is in line with the findings of other studies: in Iran, farmers had a positive intention to use improved natural grassland management practices on farmland (Yazdanpanah et al., 2014) and to use climate information for adoption of agricultural practices and improved technologies (Sharifzadeh et al., 2012). Also in Italy, Mexico and Haiti the majority of farmers had a positive intention towards the adoption of sustainable management practices (Menozzi et al., 2015; Bayard and Jolly, 2007; Martínez-García et al., 2013).

The findings in this section support hypothesis $\left(\mathrm{H}_{1}\right)$ which suggests that the majority of farmers have positive attitudes and intentions towards minimum tillage and row planting. Some farmers have negative attitudes/intentions towards both sustainable practices, although there are no respondents who have highly negative attitudes/intentions. The negative attitude might be linked to a shortage of family labour to execute the practices or a lack of awareness about the benefits of these practices. An independent chi-square test is used to understand the difference in the farmers' attitudes and intentions towards the practices and we found that both attitudes and intentions of farmers differed significantly between minimum tillage and row planting. Nevertheless, the overall attitudes and intentions of smallholder farmers for both sustainable practices seem good.

The percentage of farmers who have positive attitudes and intentions was significantly higher for row planting than minimum tillage. This might be linked to the recent government agenda. Extension workers and agricultural officials have motivated smallholder farmers to use row planting and this might explain the more positive attitudes and intentions towards row planting. Furthermore, minimum tillage requires relatively more resources and equipment, which might also explain the results. This shows the importance of enhancing awareness and solving liquidity constraints when stimulating smallholder farmers to adopt sustainable agricultural practices.

\subsection{Socio-psychological effects on smallholder farmers' behavioural intentions}

In this section, we examine determinant factors for smallholder farmers' intentions towards minimum tillage and row planting using a structural equation model. The findings from the structural equation model include the path coefficients, their significance, and explanatory power ${ }^{9}$ and are depicted in Table 3 . Based on the Lagrange multiplier test, or modification index, we modify our conceptual framework (Fig. 1) because we found direct paths from social capital and technical training to attitudes. Table 3 includes many non-significant paths. These are retained to ensure that the model is not over-fitted to the data (Price and Leviston, 2014). We also checked the goodness-of-fit and stability of the estimates using a cross-validation index, relative non-centrality index, relative fit index, non-centrality parameter, and stability index. The values of the indices fall within the recommended ranges. Thus, our model is significant overall and our estimates are stable. The estimates can thus be used for further investigation (Annex C).

As shown in the conceptual framework, the behavioural intention is explained by attitudes, perceived control and normative issues. These variables are able to predict about $81 \%$ of the available variance of intentions towards row planting and about $79 \%$ for minimum tillage. Attitudes and normative issues are statistically significant predictors that influence farmers' intentions to adopt both sustainable practices. The respondents who have positive attitudes have higher intentions towards adopting minimum tillage (by the standardised coefficient of 0.05) and row planting (by the standardised coefficient of 0.97), compared to other farmers. The normative issues positively and significantly enhance farmers' intentions to adopt both sustainable practices, with a standardised coefficient of 0.03 for row planting and 0.45 for minimum tillage.

The perceived control fails to reach statistical significance for row planting, although it has a significant negative influence on farmers' intentions to adopt minimum tillage. Farmers perceive that minimum tillage requires facilities such as labour and money, which adversely influences them. The intended behaviour for row planting is most influenced by attitudes, while minimum tillage is most affected by normative issues, because both these variables have the highest loading estimates. The findings support hypothesis $\left(\mathrm{H}_{2}\right)$ which proposed the positive and significant effect of attitudes, normative issues and perceived control on farmers' intentions towards row planting. However, perceived control is not a significant factor explaining intention towards the adoption of minimum tillage.

Table 3 also indicates that the three innovation characteristics (perceived ease of operation, perceived usefulness, perceived compatibility), social influence and technical training predict attitudes. These variables capture about $83 \%$ and $80 \%$ of the available variance in attitudes towards row planting and minimum tillage, respectively. The variables are positive and significant determinants of attitudes towards both practices, except the perceived compatibility which has a profound negative effect on attitudes towards

\footnotetext{
9 Equals coefficient of determination $\left(\mathrm{R}^{2}\right)$ and refers to the amount of variance of a model explained by the prevailing independent variables. As a rule-of-thumb, structural equations with above $0.67,0.67-0.33,0.33-0.19$, and a coefficient of determination less than 0.19 are respectively considered as a model that has substantial, moderate, weak and undesirable/unacceptable predictive power (Kline, 2011).
} 
Table 3

Standardised coefficients of variables for both practices (structural model).

\begin{tabular}{|c|c|c|c|c|c|c|c|}
\hline \multirow[t]{2}{*}{ Model } & \multirow[t]{2}{*}{ Variable } & \multicolumn{3}{|c|}{ Row planting practices } & \multicolumn{3}{|c|}{ Minimum tillage practices } \\
\hline & & Coeff. & P-value & $\mathrm{R}^{2}$ & Coeff. & P-value & $\mathrm{R}^{2}$ \\
\hline \multirow[t]{12}{*}{ Intention } & attitude & 0.97 & $0.000^{* * *}$ & 0.81 & 0.05 & $0.031^{* *}$ & 0.79 \\
\hline & normative issues & 0.03 & $0.046^{* *}$ & & 0.45 & $0.000^{* * *}$ & \\
\hline & perceived control & 0.01 & 0.651 & & -0.08 & $0.052^{*}$ & \\
\hline & perceived usefulness $^{a}$ & 0.61 & $0.000^{* * *}$ & & 0.02 & 0.329 & \\
\hline & perceived compatibility & 0.08 & $0.013^{* *}$ & & -0.01 & 0.332 & \\
\hline & perceived easiness $^{a}$ & 0.27 & $0.000^{* * *}$ & & 0.01 & $0.049^{* *}$ & \\
\hline & media influence ${ }^{a}$ & 0.03 & 0.225 & & 0.03 & 0.339 & \\
\hline & extension service $^{a}$ & 0.01 & 0.492 & & -0.03 & 0.175 & \\
\hline & technical training ${ }^{a}$ & 0.06 & $0.048^{* *}$ & & 0.06 & $0.056^{*}$ & \\
\hline & social capital $^{\mathrm{a}}$ & 0.02 & $0.027^{* *}$ & & 0.09 & $0.050^{* *}$ & \\
\hline & personal efficacy $^{\mathrm{a}}$ & 0.01 & 0.651 & & 0.04 & 0.108 & \\
\hline & perceived resource ${ }^{a}$ & 0.01 & 0.684 & & 0.01 & 0.564 & \\
\hline \multirow[t]{5}{*}{ Attitude } & perceived usefulness & 0.62 & $0.000^{* * *}$ & 0.83 & 0.47 & $0.000^{* * *}$ & 0.80 \\
\hline & perceived compatibility & 0.02 & 0.113 & & -0.23 & $0.000^{* * *}$ & \\
\hline & perceived easiness & 0.20 & $0.000^{* * *}$ & & 0.16 & $0.000^{* * *}$ & \\
\hline & social capital & 0.19 & $0.003^{* * *}$ & & 0.21 & $0.000^{* * *}$ & \\
\hline & technical training & 0.13 & $0.049^{* *}$ & & 0.01 & 0.125 & \\
\hline \multirow[t]{4}{*}{ Normative issue } & media influence & 0.11 & 0.107 & 0.70 & 0.06 & 0.340 & 0.89 \\
\hline & technical training & 0.27 & $0.000^{* * *}$ & & 0.07 & $0.036^{* *}$ & \\
\hline & extension service & 0.04 & 0.455 & & -0.13 & $0.049^{* *}$ & \\
\hline & social capital & 0.56 & $0.000^{* * *}$ & & 0.11 & $0.046^{* *}$ & \\
\hline \multirow{2}{*}{ Perceived control } & personal efficacy & 0.85 & $0.000^{* * *}$ & 0.72 & 0.09 & $0.083^{*}$ & 0.67 \\
\hline & perceived resources & 0.01 & 0.468 & & 0.03 & $-0.059^{*}$ & \\
\hline
\end{tabular}

Note:

a Shows indirect effects of the variables on farmers' intentions to adopt sustainable practices.

minimum tillage. Farmers who have technical training and strong social capital have favourable and positive attitudes towards sustainable practices. When farmers perceive practices to be useful for them, their standardised attitudes significantly improve by about $62 \%$ for row planting and $47 \%$ for minimum tillage.

Similarly, when farmers know that practices are easy to understand, learn and adopt, their attitudes towards them are considerably enhanced by the standardised coefficient of $20 \%$ for row planting and $16 \%$ for minimum tillage. This finding is consistent with the argument that technologies that are perceived to be easier to use and that are considered useful have a higher probability of acceptance and use by potential users (Shih and Fang, 2004). In Belgium, perceived difficulty significantly influenced farmers' intentions towards buffer strips, although not towards reduced tillage (Wauters, 2010). Perceived advantages and lack of complexity were also found to be main determinants for adoption of grassed waterways, filter strips, conservation tillage, and cover crops in the USA (Reimer et al., 2012).

Farmers can adopt technologies that are consistent with their existing values, past experience, current farming systems, and needs. The results show that perceived compatibility has a significant negative effect on attitudes towards minimum tillage (with a standardised coefficient of 0.23 ). This means that minimum tillage is considered non-compatible with the existing individual and social farming norms. This might be due to lack of information about the benefits of this practice. A related finding was reported by Reimer et al. (2012) for the USA where perceived compatibility was found to be one of the main determinants for adoption of grassed waterways, filter strips, conservation tillage, and cover crops. The characteristics of the practices and alternative sources of information are therefore essential factors for smallholder farmers to have positive attitudes towards sustainable agricultural practices.

The normative issues, which represent the influence of reference groups and external forces, is explained by four variables, namely, the influence of media, extension services, technical training and social capital. According to Table 3, the available variance of normative issues captured by these variables is about $70 \%$ for row planting and $89 \%$ for minimum tillage. Technical training and social capital have positive and significant effects on the normative issues for both sustainable practices. The media does not seem to have a significant effect on farmers' normative issues with regard to the adoption of either sustainable practice. The standardised coefficient is relatively higher for social capital $(\beta=0.56)$ in row planting. Thus, technical training and social capital could help farmers to reduce their uncertainty about the sustainable practices and to critically evaluate their decision-making processes.

Extension services are hypothesised to positively influence the normative issues of farmers in adopting sustainable practices. The research by Opara (2008) supported this hypothesis. However, in this study, extension services have a significant negative effect on the normative issues of farmers for minimum tillage. Farmers who have frequently acquired information and guidance from agricultural experts and extension workers have negative normative beliefs and are unlikely to use minimum tillage. Further investigation is required to better understand this negative effect of extension services on normative issues.

A similar finding was reported in Switzerland. Communication through diverse information channels positively influenced the intentions of farmers to convert from conventional farming to organic farming. Communication was also significantly explained by attitudes and subjective norms, while perceived control was found to be an insignificant factor. Furthermore, communication mediates the positive and significant effects of attitude, subjective norms and perceived control on farmers' intentions to convert to organic farming (Tutkun et al., 2006). Georgian farmers who exhibited higher levels of social capital had adopted sustainable practices more often than those who exhibited lower levels of social capital (Jordan, 2005). Thus, the target of policy makers should be to strengthen social networks and organise frequent training sessions to motivate farmers to adopt sustainable agricultural practices.

Perceived control is explained by personal efficacy (internal forces) and perceived resources (external forces). Both variables are able to predict $72 \%$ (row planting) and $67 \%$ (minimum tillage) of the available variance in perceived control. Personal efficacy, which is a farmer's self-judgment of his capabilities and skills to adopt 
sustainable practices, is a positive and significant determinant of perceived control for both agricultural practices. The standardised effect of personal efficacy on perceived control is about $85 \%$ for row planting and $9 \%$ for minimum tillage. The path from perceived resource to perceived control for minimum tillage is negative and statistically significant, although it is found to be statistically insignificant for row planting. This indicates that the presence of barriers such as a shortage of family labour and lack of money might hinder the adoption of minimum tillage. This finding confirms previous studies. In the Netherlands, technology and resource conditions greatly affected people's perception of the benefits of good environmental quality (Bayard and Jolly, 2007).

The structural model also substantiates the indirect effects of different exogenous variables on farmers' intentions towards the adoption of sustainable practices. The variables that have positive and indirect effects could improve the predictive power of intention towards both sustainable practices. Perceived usefulness, perceived ease of operation, and perceived compatibility have positive and indirect effects on farmers' intentions to adopt row planting, while it is only perceived ease of operation that has a positive indirect effect on intention towards minimum tillage. This finding supports hypothesis $\left(\mathrm{H}_{3}\right)$ which stated that attitudes mediate the positive effect of perceived usefulness, perceived ease of operation, and perceived compatibility on farmers' intentions to adopt row planting. However, with the exception of perceived ease of operation, this hypothesis could not be supported for minimum tillage.

Table 3 also shows that technical training and social capital have significant positive and indirect effects on smallholder farmers' intentions to adopt minimum tillage and row planting. Hypothesis $\left(\mathrm{H}_{4}\right)$ which states that normative issues mediate the positive and significant effects of social capital and training on intentions was supported for both sustainable practices. On the other hand, a positive and significant mediation effect for media influence and extension services on intentions could not be identified. Finally, it was also hypothesised $\left(\mathrm{H}_{5}\right)$ that perceived control would mediate positive and indirect effects of personal efficacy and perceived resources on intentions. However, this was also not supported by our data.

Interestingly, the findings from the structural equation model indicate that the different sources of agricultural information have important and substantial roles (direct and indirect) in changing the attitudes and intentions of smallholder farmers and then positively stimulating the adoption of sustainable agricultural practices in the study area. The intentions of farmers to use minimum tillage and row planting are also influenced by the evaluation (favourable and unfavourable) by farmers of the practices and the level of influence of reference groups on the farmers' behaviour. Information, attitudes, personal efficacy and normative issues thus have a great impact on smallholder farmers' behavioural intentions and decision-making processes.

\section{Conclusion and suggestions}

This study examines how socio-psychological factors and alternative information sources affect smallholder farmers' behavioural intentions to adopt minimum tillage and row planting in Ethiopia. The decomposed theory of planned behaviour is used as a theoretical basis, and the data is analysed using a linear structural equation model. The findings reveal that positive attitudes and favourable normative issues lead to stronger intentions to adopt sustainable practices. The greater the perceived control, the stronger the farmers' intention to adopt minimum tillage practices. For row planting, perceived control, however, was not a significant factor for intention.

The results also show that social capital, extension services, personal efficacy, and training are the main drivers for normative issues while, for attitude, the main drivers are practice attributes along with social capital and training. Also, attitude mediates the positive effects of perceived usefulness and perceived ease of operation on farmers' intentions to adopt sustainable practices. Similarly, the normative issues mediate the positive and significant effects of training and social capital on intentions towards sustainable practices. However, mass media and extension services have no indirect effect on farmers' intentions. Perceived control is also found to be an insignificant mediator for the effects of personal efficacy and perceived resource on farmers' intentions. Thus, practice attributes and alternative information are essential factors for farmers to have a positive attitude, favourable normative issues and high intentions towards sustainable practices.

Two implications can be identified from this study (a) sociopsychological factors are influential factors in the smallholder farmers' adoption behaviour and decision-making processes. Accordingly, merely providing economic resources and facilities is not enough to promote sustainable practices. Attention should also be paid to socio-psychological issues in developmental and promotional campaigns (b) the behavioural theoretical framework appears to sufficiently explain the intentions of smallholder farmers. Consequently, this paper can serve as a reference in the literature by providing valuable information, and it can motivate researchers to use a behavioural framework in agricultural and rural development studies. Policy makers and development practitioners should motivate smallholder farmers to adopt sustainable practices by emphasising and reinforcing social capital and agricultural advisory services, as well as the use of media channels and provision of intensive training in capacity building.

A number of potential limitations can be identified. First, unlike the previous behavioural studies, which used seven-point Likert scales, we applied a five-point scale to measure our observed indicators. This choice was made to avoid ambiguity for the local farmers. In addition, this paper focused on behavioural intentions rather than actual use (adoption) of sustainable practices. While the behavioural intention is a necessary condition, it is not a sufficient condition for actual adoption. Furthermore, demographic characteristics are not considered, although such variables are expected to have direct and indirect effects on intentions, attitudes, normative issues and perceived controls. Accordingly, the results may suffer from an omitted variable bias. Finally, the data in this study is from only one drought-affected district in Ethiopia and thus cannot be automatically extrapolated to the rest of the country. Nevertheless, the findings of the study are still valuable.

Future research could focus on how demographic variables affect variance in attitudes, normative issues and intentions concerning the adoption of sustainable practices. For example, it would be interesting to study the effect of gender or cultural differences on the adoption and decision behaviour of farmers. Furthermore, more comprehensive studies in terms of the number of agricultural practices considered with a larger geographical spread or incorporating a time aspect could increase our understanding. Such studies could allow the design of specific interventions to motivate farmers to adopt sustainable practices, which could have a positive effect on food security and environmental issues.

\section{Acknowledgment}

The research cost of this study is covered and supported by Ghent University, Mekelle University, and Open Society Foundations-Africa Climate Change Adaptation Initiative (ACCAI). We would, therefore, like to express our deep appreciation for the organisations. We are also grateful for the farmers who shared their time and provided valuable information. 


\section{Appendix A. Supplementary data}

Supplementary data related to this article can be found at http://

dx.doi.org/10.1016/j.jenvman.2016.11.014.

Annex A

Summary statistics, normality, reliability, and validity for the variables in the study

\begin{tabular}{|c|c|c|c|c|c|c|c|c|c|c|c|}
\hline \multirow[t]{2}{*}{ Variable } & \multirow[t]{2}{*}{ Statements } & \multicolumn{5}{|c|}{ Row planting practices } & \multicolumn{5}{|c|}{ Minimum tillage practices } \\
\hline & & Mean & $\alpha$ & AFL & AVE & SKW & Mean & $\alpha$ & AFL & AVE & SKW \\
\hline Intentions & 6 & 3.27 & 0.94 & 0.88 & 0.78 & 0.08 & 2.90 & 0.85 & 0.73 & 0.66 & 0.07 \\
\hline Attitudes & 4 & 3.46 & 0.91 & 0.88 & 0.79 & 0.09 & 2.99 & 0.83 & 0.79 & 0.67 & -0.72 \\
\hline Normative issues & 5 & 3.69 & 0.94 & 0.90 & 0.81 & 0.11 & 3.46 & 0.85 & 0.79 & 0.72 & -0.63 \\
\hline Perceived control & 3 & 2.89 & 0.90 & 0.91 & 0.84 & 0.24 & 3.00 & 0.86 & 0.87 & 0.81 & 0.20 \\
\hline Perceived usefulness & 3 & 2.73 & 0.84 & 0.96 & 0.75 & 0.22 & 2.92 & 0.72 & 0.76 & 0.63 & 0.31 \\
\hline Perceived easiness & 3 & 2.71 & 0.88 & 0.90 & 0.81 & -0.01 & 2.74 & 0.77 & 0.81 & 0.74 & 0.20 \\
\hline Perceived compatibility & 3 & 2.63 & 0.71 & 0.68 & 0.67 & 0.52 & 2.49 & 0.92 & 0.75 & 0.75 & 0.31 \\
\hline Media influence & 3 & 3.31 & 0.84 & 0.86 & 0.77 & 0.26 & 3.02 & 0.74 & 0.63 & 0.53 & -0.77 \\
\hline Technical training & 4 & 3.35 & 0.89 & 0.86 & 0.77 & 0.44 & 2.67 & 0.81 & 0.78 & 0.68 & -0.43 \\
\hline Social capital & 5 & 3.49 & 0.92 & 0.87 & 0.76 & -0.06 & 2.87 & 0.81 & 0.75 & 0.66 & -0.19 \\
\hline Extension service & 3 & 3.30 & 0.73 & 0.81 & 0.67 & -0.08 & 2.78 & 0.71 & 0.72 & 0.55 & 0.35 \\
\hline Personal efficacy & 5 & 3.16 & 0.88 & 0.81 & 0.70 & -0.02 & 2.86 & 0.82 & 0.74 & 0.62 & -0.51 \\
\hline Perceived resource & 3 & 3.21 & 0.87 & 0.89 & 0.81 & -0.01 & 3.01 & 0.78 & 0.64 & 0.62 & -0.05 \\
\hline
\end{tabular}

Note: Annex B and C are supplementary materials, which can be found online or obtained on request.

\section{References}

Ajzen, I., 1991. The theory of planned behavior. Organ. Behav. Hum. Decis. Process. $50,179-211$.

Araya, T., 2012. Conservation Agriculture-based Resource Saving Technology for Land Resilience in Northern Ethiopia. Ghent University. PhD thesis.

Asfaw, S., et al., 2012. Impact of modern agricultural technologies on smallholder welfare: evidence from Tanzania and Ethiopia. Food Policy 37 (3), 283-295.

Bayard, B., Jolly, C., 2007. Environmental perceptions and behavioral change of hillside farmers: the case of Haiti. J. Caribb. Agro-Economic Soc. 7 (1), 122-138.

Borges, J.A.R., et al., 2014. Understanding farmers' intention to adopt improved natural grassland using the theory of planned behavior. Livest. Sci. 169, $163-174$.

Dillon, A., 2011. The effect of irrigation on poverty reduction, asset accumulation and informal insurance: evidence from Northern Mali. World Dev. 39 (12) 2165-2175.

Ekeberg, E., Riley, H.C.F., 1997. Tillage intensity effects on soil properties and crop yields in a long-term trial on morainic loam soil in southeast Norway. Soil Tillage Res. 42 (4), 277-293.

FAO, 2014. The State of Food and Agriculture: Innovation in Family Farming (Rome).

Fielding, K.S., et al., 2005. Explaining landholders' decisions about riparian zone management: the role of behavioural, normative, and control beliefs. J. Environ. Manag. 77, 12-21.

Fishbein, M., Ajzen, L., 1975. Belief, Attitude, Intention, and Behaviour: an Introduction to Theory and Research. Addison-Wesley, Reading, MA.

Foley, K.M., 2013. Examining the Voluntary Adoption of Agricultural Conservation Practices in Northern Malheur Country, Oregon. Oregon State University. Master thesis.

Gumataw, A., et al., 2013. Adoption of improved potato varieties in Ethiopia: the role of agricultural knowledge and innovation system and smallholder farmers' quality assessment. Agric. Syst. 122, 22-32.

Hattam, C., 2006. Adopting organic agriculture: an investigation using the Theory of Planned Behaviour. In: International Association of Agricultural Economics Conference.

Herath, C.S., 2013. Does intention lead to behaviour? A case study of the Czech Republic farmers. Agric. Economics-Czech 59 (3), 143-148.

Iqbal, T., El-Gohary, E., 2014. An attempt to understand e-marketing: an information technology prospective. Int. J. Bus. Soc. Sci. 5 (4), 234-256.

Jordan, J.L., 2005. Farmers' choice of using sustainable agricultural practices: a social capital approach. In: The Southern Agricultural Economics Association Annual Meeting, pp. 1-25. Arkansas.

Kassie, M., et al., 2013. Adoption of interrelated sustainable agricultural practices in smallholder systems: evidence from rural Tanzania. Technol. Forecast. Soc. Change 80, 525-540.

Kelsey, J.B., 2013. Constraints on the adoption of agricultural technologies in developing countries. Literature submitted for publication. In: Agricultural Technology Adoption Initiative. J-PAL (MIT) and CEGA, (UC Berkeley).

Kline, R.B., 2011. In: Kenny, D., Little, T. (Eds.), Principles and Practice of Structural Equation Modeling, third ed. The Guilford Press, New York, USA.

Kyere-Duodu, K., 2011. Adoption of Internet Banking Among Ghanaian Consumers a Study Using Decomposed Theory of Planned Behaviour. Luleå University of Technology. Master thesis.
Läpple, D., Kelley, H., 2010. Understanding farmers' uptake of organic farming: an application of the theory of planned behaviour. In: The 84th Annual Conference of the Agricultural Economics Society, pp. 1-29.

Lee, D.R., 2005. Agricultural sustainability and technology adoption: issues and policies for developing countries. Am. J. Agric. Econ. 87 (5), 1325-1334.

Lobb, A.E., Mazzocchi, M., Traill, W.B., 2007. Modelling risk perception and trust in food safety information within the theory of planned behaviour. Food Qual. Prefer. 18 (2), 384-395.

Martínez-García, C.G., Dorward, P., Rehman, T., 2013. Factors influencing adoption of improved grassland management by small-scale dairy farmers in centra Mexico and the implications for future research on smallholder adoption in developing countries. Livest. Sci. 152 (2-3), 228-238.

Mbow, C., et al., 2014. Achieving mitigation and adaptation to climate change through sustainable agroforestry practices in Africa. Curr. Opin. Environ. Sustain. 6, 8-14.

Menozzi, D., Fioravenzi, M., Donati, M., 2015. Farmer's motivation to adopt sustainable agricultural practices. Bio-based Appl. Econ. 4 (2), 125-147.

Norton, G., Alwang, J., Masters, W., 2010. Economics of Agricultural Development: World Food Systems and Resource Use, 2nd. Routledge Taylor and Francis Group, London.

Opara, U.N., 2008. Agricultural information sources used by farmers in Imo State, Nigeria. Inf. Dev. 24, 289-295.

Power, E.F., Kelly, D.L., Stout, J.C., 2013. Impacts of organic and conventional dairy farmer attitude, behaviour and knowledge on farm biodiversity in Ireland. J. Nat. Conserv. 21 (5), 272-278.

Price, J.C., Leviston, Z., 2014. Predicting pro-environmental agricultural practices: the social, psychological and contextual influences on land management. J. Rural Stud. 34, 65-78.

Reimer, A.P., Weinkauf, D.K., Prokopy, L.S., 2012. The influence of perceptions of practice characteristics: an examination of agricultural best management practice adoption in two Indiana watersheds. J. Rural Stud. 28, 118-128.

Rogers, E., 1983. Diffusion of Innovations, 3rd. The Free Press.

Sadaf, A., Newby, T.J., Ertmer, P., 2012. Exploring factors that predict preservice teachers' intentions to use Web 2.0 technologies using decomposed theory of planned behavior. J. Res. Technol. Educ. 45 (2), 171-195.

Sharifzadeh, M., et al., 2012. Agricultural climate information use: an application of the Planned Behaviour Theory. J. Agric. Sci. Technol. 14 (2), 479-492.

Shih, Y., Fang, K., 2004. The use of a decomposed theory of planned behavior to study Internet banking in Taiwan. Internet Res. 14 (3), 213-223.

Tam, D.M.Y., Coleman, H., 2011. Validation study of a gatekeeping attitude index for social work education. J. Teach. Soc. Work 31 (5), 505-522.

Taylor, S., Todd, P., 1995. Decomposition and crossover effects in the theory of planned behavior: a study of consumer adoption intentions. Int. J. Res. Mark. 12, 137-155.

Teklewold, H., Kassie, M., Shiferaw, B., 2013. Adoption of multiple sustainable agricultural practices in rural Ethiopia. J. Agric. Econ. 64 (3), 597-623.

Terano, R., et al., 2015. Factors influencing intention to adopt sustainable agriculture practices among paddy farmers in Kada, Malaysia. Asian J. Agric. Res. 9 (5), 268-275.

Todaro, YmP., Smith, S.C., 2011. Economic Development:the Developed and Developing World, 11th. Addison-Wesley, Boston, USA.

Tutkun, A., Lehmann, B., Schmidt, P., 2006. Explaining the conversion to organic farming of farmers of the Obwalden Canton, Switzerland - extension of the 
theory of planned behavior within a structural equation modeling approach. In: The 80th Annual Conference of the Agricultural Economics Society. Agri-food and Agri-environmental Economics Group, Swiss Federal Institute of Technol ogy, Zurich, Switzerland.

Vandercasteelen, J., et al., 2014. Perceptions, Impacts and Rewards of Row Planting of Teff, No 65, ESSP Working Papers. International Food Policy Research Institute (IFPRI).

Veisi, H., Toulabi, S.B., 2012. Factors influencing pro-environmental behaviour in agriculture. In: International Conference on Ecological, Environmental and Biological Sciences. Environmental Sciences Research Institute, Dubai, pp. 346-349. Shahid Beheshti University.

Velarde, V.D.V., 2012. Determinants of Online Purchasing Behavior: an Empirica Investigation Using an Extension of the Theory of Planned Behavior. Aarhus University.

Venkatesh, V., Thong, J.Y.L., Xu, X., 2012. Consumer acceptance and use of information technology: extending the unified theory of acceptance and use of technology. MIS Q. 36 (1), 157-178.

Wauters, E., 2010. The Use of Social Psychology for Improving the Adoption of Conservation Practices Soil Conservation in Belgium. Faculty of Bioscience
Engineering KULeuven. PhD thesis.

Wauters, E., Mathijs, E., 2014. The adoption of farm level soil conservation practices in developed countries: a meta-analytic review. Int. J. Agric. Resour. Gov. Ecol. 10 (1), 78-102.

Wezel, A., et al., 2014. Agroecological Practices Supporting the Provision of Goods and Services in Agriculture Examples from France and Europe.

Wollni, M., Lee, D.R., Thies, J.E., 2010. Conservation agriculture, organic marketing, and collective action in the Honduran hillsides. Agric. Econ. 41, 373-384.

Yamane, T., 1967. Statistics: an Introductory Analysis, second ed. Harper and Row, New York.

Yamano, T., Rajendran, S., Malabayabas, M., 2013. Determinants of Psychological Constructs toward Agricultural Technology Adoption: Evidence from Eastern India.

Yazdanpanah, M., et al., 2014. Understanding farmers' intention and behavior regarding water conservation in the Middle-East and North Africa: a case study in Iran. J. Environ. Manag. 135, 63-72.

Zschocke, T., et al., 2013. Readiness to use e-learning for agricultural higher education in Sub-Saharan Africa. Results a Surv. Fac. Members. 4 (1), 37-47. 